\title{
Fine mapping and marker-assisted selection (MAS) of a low glutelin content gene in rice
}

\author{
Yi Hua WANG ${ }^{1}$, Shi Jia LIU ${ }^{1}$, Su Lan JI ${ }^{1}$, Wen Wei ZHANG ${ }^{1}$, Chun Ming WANG ${ }^{1}$, Ling JIANG ${ }^{1}$, Jian Min WAN ${ }^{1,2, *}$ \\ ${ }^{1}$ The State Key Laboratory of Crop Genetics and Germplasm Enhancement, Nanjing Agricultural University; Jiangsu Re- \\ search Center of Plant Engineering, Nanjing 210095, China \\ ${ }^{2}$ Crop Science Research Institute, Chinese Academy of Agricultural Science, Beijing 100081, China
}

\begin{abstract}
Rice with low glutelin content is suitable as functional food for patients affected with diabetes and kidney failure. The fine mapping of the gene(s) responsible for low glutelin content will provide information regarding the distribution of glutelin related genes in rice genome and will generate markers for the selection of low glutelin rice varieties. Following an SDS-PAGE screen of rice germplasm from Taihu Valley of China, Japonica selection W3660 is identified to be a novel mutant characterized with low glutelin content. For fine mapping the mutant gene for low glutelin content, $\mathrm{F}_{2}$ and $\mathrm{F}_{3}$ populations were derived from a cross between W3660 and Jingrennuo. SDS-PAGE analysis of the total endosperm protein showed that the low glutelin content trait was controlled by a single dominant nuclear gene. Genetic mapping, using SSRs, located this gene to chromosome 2, in the region between SSR2-001/SSR2-004 and RM1358. The distances of the two markers to the target gene were $1.1 \mathrm{cM}$ and $3.8 \mathrm{cM}$ respectively. By semi-quantitative RT-PCR analysis, the transcripts of GluB4/GluB5 genes located within the region do not change. However, GluB5 gene located proximal to SSR2-001/SSR2-004 was specifically reduced. SSR profiles of seven Japonica varieties were compared with that of W3660 for loci in the relevant genetic region. The markers SSR2-004 and RM1358 were used for markerassisted selection. The selection efficiencies of SSR2-004 and RM1358 were $96.8 \%$ and $92.7 \%$ respectively. This provides a standard starting point for the breeding of low glutelin content rice varieties in China.
\end{abstract}

Keywords: fine mapping, low glutelin content, marker-assisted selection, mutant, rice.

\section{INTRODUCTION}

Rice (Oryza sativa L.) is considered to be a starchy crop because of its relatively low protein content, which ranges from $7 \%$ to $10 \%$ of the grain weight. However, rice is an important protein source for human consumption, especially in Asian and Indian subcontinents. The demand for rice as a source of dietary protein is expected to increase significantly along with the world population, which is predicted to double by 2030 [1]. Glutelin is the major digestible component of the rice storage proteins, and accounts for $60 \%$ of total seed protein. It is localized in protein body II (PBII) within endosperm cells, while the indigestible prolamine fraction, account-

*Correspondence: Jian Min WAN

Tel/Fax: +86-025-84396516;

E-mail: wanjm@njau.edu.cn ing for $5 \sim 10 \%$ of total seed protein, is contained in PBI. Increasing the glutelin content and lowering prolamine content of rice grains would improve the nutritional value of rice. However, for patients affected with diabetes and kidney failure, the significant consumption of glutelin can lead to exacerbated medical problems. For example, in China there are more than 80 million people who have been diagnosed with diabetes and kidney failure. It is estimated that $35 \%$ and $15 \%$ of type I and II diabetic patients have complicated renal failure, which leads to serious disturbance of protein metabolism. These patients cannot ingest rice grains with soluble protein content above $4 \%$. Iida et al obtained a rice mutant LGC-1, which was characterized as a low glutelin and a high prolamine content crop [2]. As demonstrated by recent studies on diabetic patients, LGC-1 rice functions as an effective supplementary food, especially for those who consume rice grains as their staple food [3]. According to Miyahara et al [4], low glutelin 
content trait in LGC-1was controlled by a single dominant gene, $L g c-1$, located between RFLP markers XNpb 243 and G365 on chromosome 2. The genetic distance separating the two markers from $L g c-1$ were estimated to be $8.5 \mathrm{cM}$ and $39.1 \mathrm{cM}$ respectively.

We recently identified three lines showing variant glutelin content from an SDS-PAGE screen of rice germplasm from Taihu Valley, China. Among them, Japonica selection W3660 has a phenotype similar to LGC-1 [5]. We are now engaged in an effort to modify the glutelin content of commercial rice varieties by transferring the W3660 trait to adapted material. For this purpose, high throughput DNA markers would be desirable, since SDS-PAGE analysis is tedious and costly to apply in a breeding programme. The object of the present study was to develop molecular markers linked to the low glutelin content trait of W3660.

\section{MATERIALS AND METHODS \\ Plant materials}

W3660 was crossed with Jingrennuo, an Indica variety with normal glutelin content, and the resulting $\mathrm{F}_{2}$ population, consisting of 194 individuals, was used for linkage mapping. The parental lines and the $F_{2}$ population were grown in the summer of 2001 in the field at the Rice Research Institute at Nanjing Agricultural University. To finely map the mutant gene, an $\mathrm{F}_{2}$ plant heterozygous for both the mutant allele and flanking markers was self-pollinated, to construct a derived $\mathrm{F}_{3}$ population $\left(\mathrm{dF}_{3}\right)$, totaling 442 individuals (Fig. 1). These plants, along with the parental lines were grown, as above, in the summer of 2002. Field management essentially followed normal agricultural conditions.

\section{Extraction of protein in rice grains and phenotype assays by SDS-PAGE}

Mature seeds were harvested from individual $F_{2}$ and derived $F_{3}$ plants, and bulk-harvested from parental plants for phenotyping by SDS-PAGE. Six seeds were selected randomly from each plant and analyzed for protein profiles by SDS-PAGE. When the protein content segregated from a sample of six seeds per plant, this plant was classified as heterozygous for the mutant allele(s). When no segregation was observed, a further sample of six seeds was analyzed to verify the allelic status as homozygous. Protein extraction was performed as described by Cagampang GB et al [6] and Iida et al [2, 7]. Briefly, seed was polished, ground, and placed in a $1.5 \mathrm{ml}$ centrifuge tube, to which was added $700 \mu 1$ SDS-Urea extract solution, consisting of $8 \mathrm{M}$ Urea, $4 \%$ SDS, $5 \% \beta$-mercaptoethanol, $20 \%$ glycerol, 50 $\mathrm{mM}$ Tris- $\mathrm{HCl}$ buffer ( $\mathrm{pH} 6.8$ ). The tube was vortexed and incubated overnight at $25^{\circ} \mathrm{C}$. After centrifugation at $7000 \mathrm{~g}$ for $5 \mathrm{~min}, 5 \mu \mathrm{lof}$ supernatant was loaded onto an SDS-PAGE gel [8]. We used a $15 \%$ polyacrylamide gel for separation, and a $7.5 \%$ gel for stacking. Following electrophoresis, gels were stained with CBB-R250.

\section{DNA extraction}

Two to three leaves were taken from each plant before heading and stored at $-80^{\circ} \mathrm{C}$. DNA was extracted from the frozen leaf tissue according to Dellapporta et al [9] with minor modification. Following extraction, the DNA was dissolved in TE buffer $(10 \mathrm{mM}$ Tris base, $0.1 \mathrm{mM}$ EDTA). DNA quality and concentration were determined with MBA2000 UV/vis spectrophotometer (Perkin Elemer Co). The stock DNA preparation was diluted to $20 \mathrm{ng} / \mu 1$ for use as templates for PCR amplification.

\section{SSR marker design}

Some of the SSR primers were taken from Temnykh S et al [10] and McCouch SR [11]. Others were directly designed from the rice genome sequences according to Rice Genome Program (RGP). For the latter, an in silico search for SSR sequences (number of repeats $>5$ ) was made in the region defined by linked flanking SSR markers in BAC/PAC clones using SSRIT (The Simple Sequence

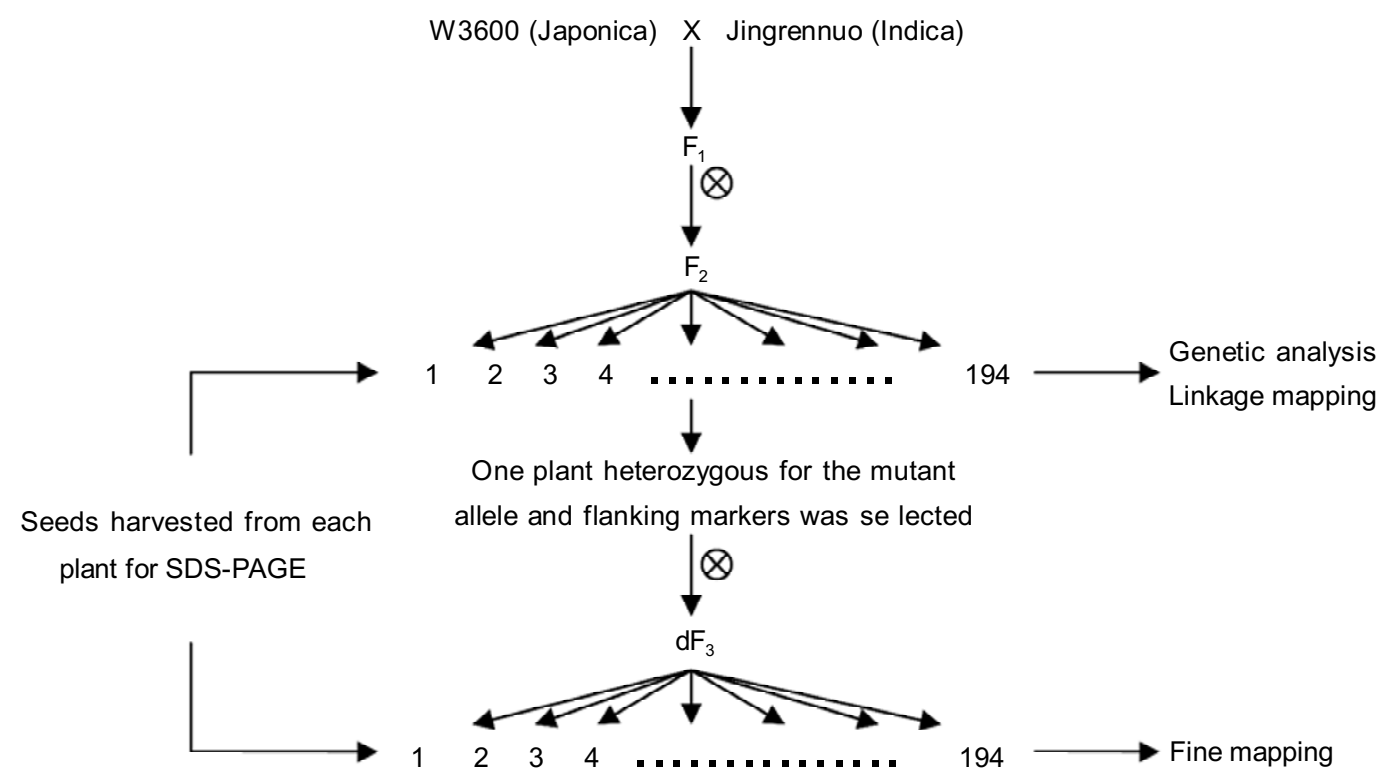

Fig. 1 Schematic diagram of genetic analysis and fine mapping of low glutelin content gene in W3660. 
Repeat Identification Tool, http://www.gramene.org/db/searches/ ssrtool). These SSR and the adjacent sequences of 400 500 bp were BLASTed against the Chinese rice genome database (http://btn. genomics.org.cn/rice) to identify Japonica/Indica polymorphism between Nipponbare and 9311. Polymorphic primers were designed using the program Primer Premier 5.0, and were tested against DNAs of W3660, Jingrennuo and their $F_{1}$ hybrid.

\section{SSR marker analysis}

SSR analysis was performed according to Chen et al [12]. Each $10 \mu 1$ PCR reaction contained 10-20 ng of template DNA, $1 \times$ PCR reaction buffer $\left(\mathrm{Mg}^{2+}\right.$ free, TaKaRa, Dalian), $1.5 \mathrm{mM}$ of $\mathrm{MgCl}_{2}, 50 \mu \mathrm{M}$ of dNTPs, $20 \mu \mathrm{M}$ of primers, and $0.5 \mathrm{U}$ of Taq DNA polymerase (TaKaRa Co). Amplification profiles consisted of $5 \mathrm{~min}$ of denaturation at $94^{\circ} \mathrm{C}, 35$ cycles of $30 \mathrm{~s}$ denaturation at $94^{\circ} \mathrm{C}, 30 \mathrm{~s}$ annealing (temperature determined by primer pair sequence), and $60 \mathrm{~s}$ extension at $72^{\circ} \mathrm{C}$, followed by a final $10 \mathrm{~min}$ extension at $72^{\circ} \mathrm{C}$. Denatured amplified products were electrophoresed through $8 \%(\mathrm{w} / \mathrm{v})$ native polyacrylamide gels at $120 \mathrm{~V}$ for ca. $3 \mathrm{~h}$, and visualized by silver staining following Sanguinetti et al [13].

\section{SSR marker-assisted selection}

Seven widely grown Japonica varieties (Xiangjing 9707, Xiangjing 119, 9924, Zhendao 88, Wuyujing 3, Zhendao 99, Wuyunjing 7) were used for marker-assisted selection breeding programme. SSR markers linked to mutant gene, identified in this study, were tested for polymorphism between these varieties and W3660. 188 plants with good agronomic performance in the field were selected from an $\mathrm{F}_{2}$ breeding population derived from the cross Wuyunjing $7 \times \mathrm{W} 3660$ for SSR and SDS-PAGE analysis to assess the efficiency of markerassisted selection. For other crosses or generations, 12 individuals were selected from each of two or three lines. DNA was extracted from young leaves according to the following method. Briefly, tissue was ground in a centrifuge tube in the presence of $40 \mu 1$ of $0.25 \mathrm{M}$ $\mathrm{NaOH}$ until the solution turned green. Then $160 \mu 1$ of $100 \mathrm{mM}$ Tris$\mathrm{HCl}$ (pH7.6) was added, and the supernatant was diluted 50-fold, for use as template for SSR analysis. PCR analysis and protein phenotyping was carried out as described above.

\section{RESULTS}

\section{Phenotype identification and genetic analysis of low} glutelin content

The protein profile revealed by SDS-PAGE analysis indicated that W3660 has less mature glutelin (37-39 kDa and $22-23 \mathrm{kDa})$ and more prolamine $(13 \mathrm{kDa})$ than Jingrennuo (Fig. 2). The trait segregated in the $F_{2}$ and derived $\mathrm{F}_{3}$ populations from the cross W3660 $\times$ Jingrennuo. The low glutelin mutant in W3660 segregated as a monogenic dominant trait, as no intermediate phenotypes were detected. Genotyping results showed the segregation pattern fitted the Mendelian ratio 1:2:1 in both populations (Tab. 1).

\section{Linkage mapping of mutant gene}

In the genome-wide polymorphism screen, $511 \mathrm{SSR}$ loci were tested for W3660, Jingrennuo and their $F_{1}$ hybrid. Polymorphic markers evenly distributed across all 12 chromosomes were obtained. Two point linkages indicated an association between loci mapping to chromosome 2 and the target trait. Thereafter, the $\mathrm{F}_{2}$ population was mapped using ten markers on chromosome 2. According to the linkage map constructed with MAPMAKER/EXP3.0 [14], the mutant gene was located between RM71 and RM424. The marker-mutant gene distances were $16.5 \mathrm{cM}$ and $12.7 \mathrm{cM}$, respectively (Fig. 3).

\section{Fine mapping of mutant gene}

One plant heterozygous for RM71, RM424 and mutant

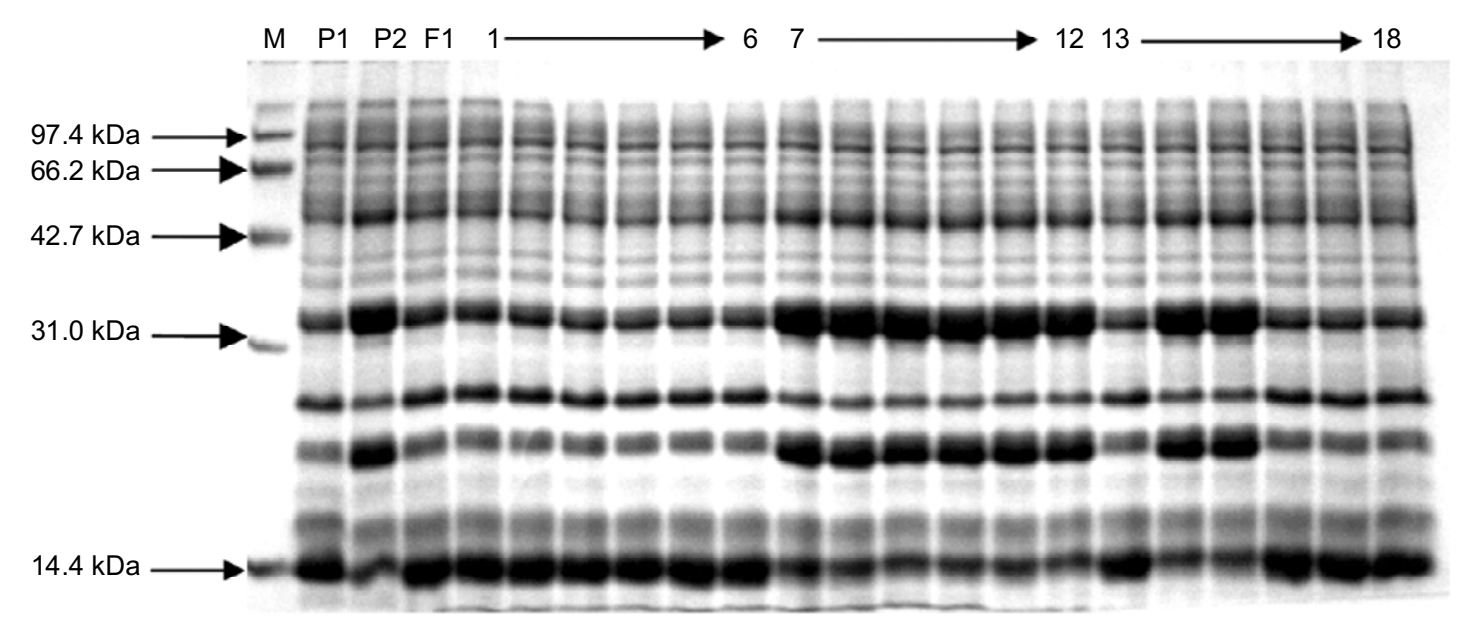

Fig. 2 SDS-PAGE analysis of total protein in $\mathrm{F}_{2:} \mathrm{F}_{3}$ seeds. M: Mid-range protein molecular weight marker; $\mathrm{P}_{1}$ : W3660; $\mathrm{P}_{2}$ : Jingrennuo; 1-6, 7-12, 13-18 are samples randomly selected from plant 45 , plant 131 and plant 402 in derived $F_{3}$ population. Plant 402 is heterozygous for the mutant allele. For plant 45 and plant131 each, another sample of six seeds needs analyzing to verify the allelic status as homozygous. 
Tab. 1 Segregation of low glutelin content in $F_{2}$ and derived $F_{3}$ populations from the cross of W3660 $\times$ Jingrennuo

\begin{tabular}{cccccc}
\hline Population & Total & $\begin{array}{c}\text { Homozygotes of } \\
\text { low glutelin }\end{array}$ & $\begin{array}{c}\text { Homozygotes of } \\
\text { low glutelin }\end{array}$ & $\begin{array}{c}\text { Homozygotes of } \\
\text { normal type }\end{array}$ & $\begin{array}{c}x^{2} \\
(1: 2: 1)\end{array}$ \\
\hline $\mathrm{F}_{2}$ & 194 & 55 & 94 & 45 & 1.21 \\
$\mathrm{dF}_{3}$ & 442 & 105 & 227 & 110 & 0.43 \\
\hline
\end{tabular}

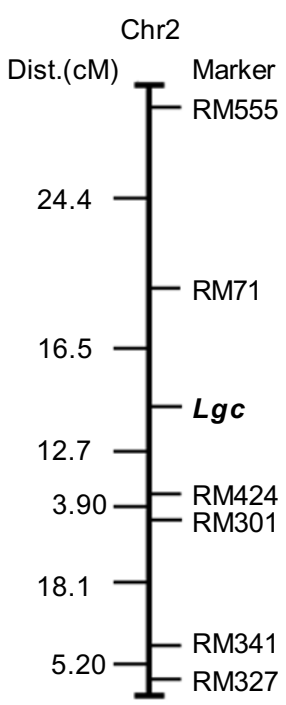

Fig. 3 Primary mapping results of mutant gene $\left(\mathrm{F}_{2}\right.$ population with 194 individuals).

gene was self-pollinated, to generate $442 \mathrm{~F}_{3}$ progenies. Eleven SSR primer loci were located in the region flanking the target gene within a range of $20 \mathrm{cM}$, but only two of these - RM7636 and RM7288 - were polymorphic between the parental cultivars. These were added to the linkage map derived from the $\mathrm{F}_{3}$ progenies. From a further eleven SSR primer pairs mapping between RM7288 and RM324, we obtained five polymorphic assays. Based on an analysis using all these markers, mutant gene was located between RM5356 and RM1358, with marker-mutant gene distances of $2.0 \mathrm{cM}$ and $3.8 \mathrm{cM}$ respectively. By referring to the genomic sequence between these two markers, we were able to design a further four pairs of SSR primers, two of which (Tab. 2), SSR2-001 and SSR2-
004 were polymorphic with respect to the parental cultivars. SSR2-001 and SSR2-004 co-segregated in the derived $\mathrm{F}_{3}$ population. Finally we estimated the map location of mutant gene as being $1.1 \mathrm{cM}$ from SSR2-001/SSR2-004 and $3.8 \mathrm{cM}$ from RM1358 (Fig. 4).

\section{GluB5 gene expression was downregulated in W3660 mutant}

There are six PAC/BAC clones, P0693E08, OSJNBa0033K18, P0521F09, P0411A13, P0017G06, 0SJNBa0055M07 covering the region between SSR2-001/

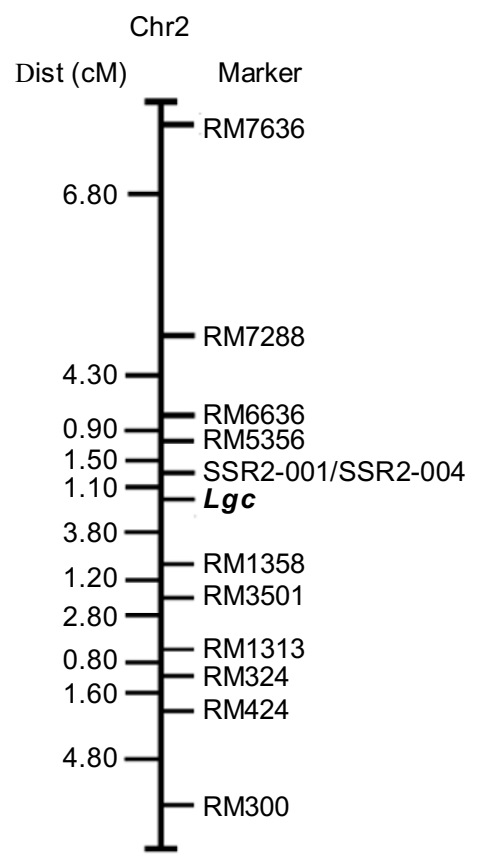

Fig. 4 Fine mapping results of mutant gene $\left(\mathrm{dF}_{3}\right.$ population with 442 individuals).

Tab. 2 Two SSR markers, linked to mutant gene, developed from an Oryza sativa var Nipponbare genome database

\begin{tabular}{clllcc}
\hline Primer & SSR motif & & Primer Sequence $\left(5^{\prime}-3{ }^{\prime}\right)$ & $\mathrm{T}_{\mathrm{a}}\left({ }^{\circ} \mathrm{C}\right)$ & Size $(\mathrm{bp})$ \\
\hline \multirow{2}{*}{ SSR2-001 } & \multirow{2}{*}{ (AT) 25} & Forward & CTGCTTTCCTCTAGTCTGT & 54 & 173 \\
& & Reverse & TGCTCATTTGAATTGGGTAT & \multirow{2}{*}{143} \\
SSR2-004 & (CTT) 16 & Forward & TTTTCGTATCCACCTTCG & 55 \\
& & Reverse & TTGCTGAGCCCGACATTA & & \\
\hline
\end{tabular}




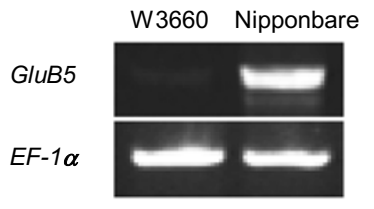

Fig. 5 Expression analysis of GluB5 in W3660 and Nipponbare by semi-quantitative RT-PCR. GluB5 (AY196922) was in the region of 37.0-37.4 cM on chromosome 2. Total RNA was extracted from endosperm of $14 \mathrm{DAF}$ (days after flowering); $E F-1 \alpha$ was used as a control.

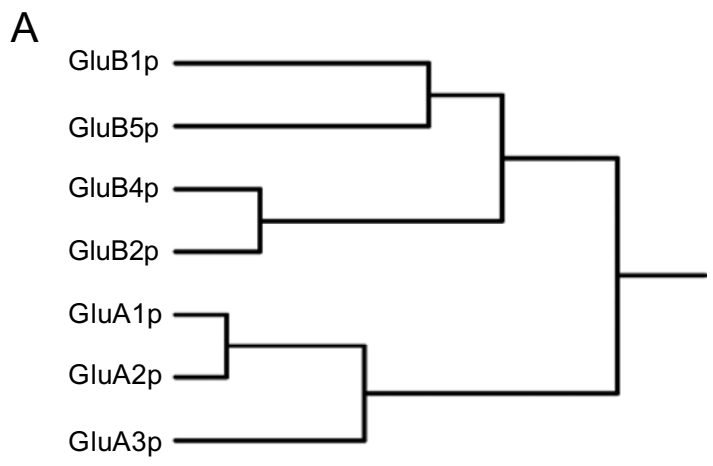

SSR2-004 and RM1358. Two highly interesting genes GluB4/GluB5 involved in glutelin synthesis are included within the region. We designed primers to analyze the expression of glutelin genes including GluA-1 (L36819), GluA-2 (AY 585231), GluA-3 (X54313), GluB-1 (X54314), GluB-2 (X54192), GluB-4 (AF537221) (referred as GluB4/GluB5 by Kusaba et al [15]), GluB-5 (AY196923) in W3660 mutant by semi-quantitative RTPCR. The only gene affected in W3660 mutant is GluB5 (AY196922) (Fig. 5), while transcripts of other Glutelin genes do not change (manuscript in preparation). GluB5 gene (AY196923) is located on chromosome 2 between $37.0 \mathrm{cM}$ to $37.4 \mathrm{cM}$. It is most closely related to $G l u B 4$ by phylogenic tree analysis (Fig. 6A) and contains all of the conserved sequences within the Glutelin gene families (Fig. 6B). GluB5 and GluB4 share over $80 \%$ amino acid sequence identity (Fig. 6B). The genomic region between SSR2-004 and RM1358 contains about 150 genes and most of them have unknown function. To further localize the mutant gene precisely, new markers are needed. Nevertheless, GluB5 gene involved in glutelin synthesis is specifically reduced in W3660 mutant.

B

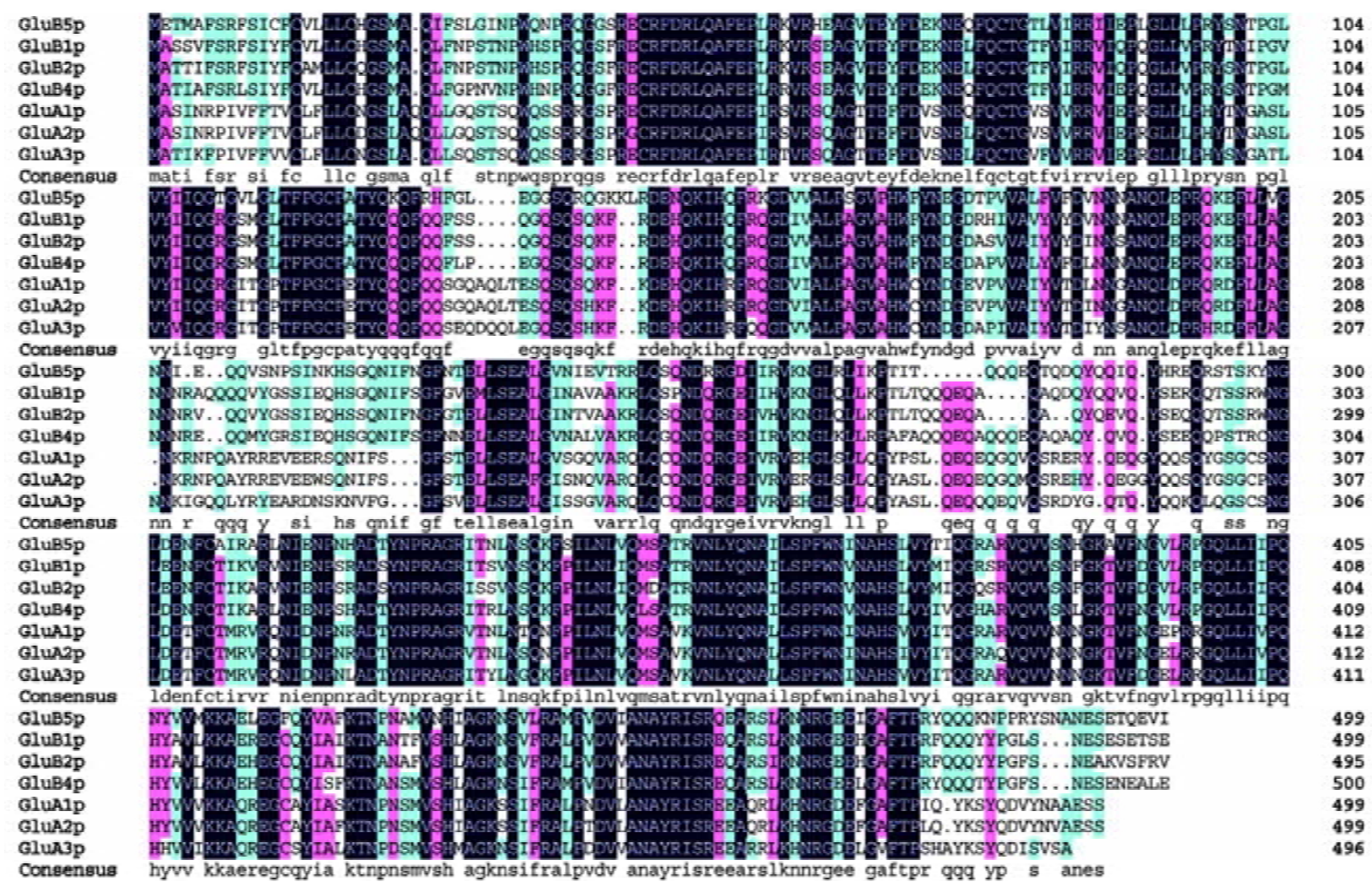

Fig. 6 Alignment of GluB5 (AY196923) with other glutelin genes. (A) Phylogenic tree of GluB5 and other glutelin genes; (B) Amino acid sequence alignment between GluB5 and other glutelin genes. The sequence alignment was done using software DNAMAN. 


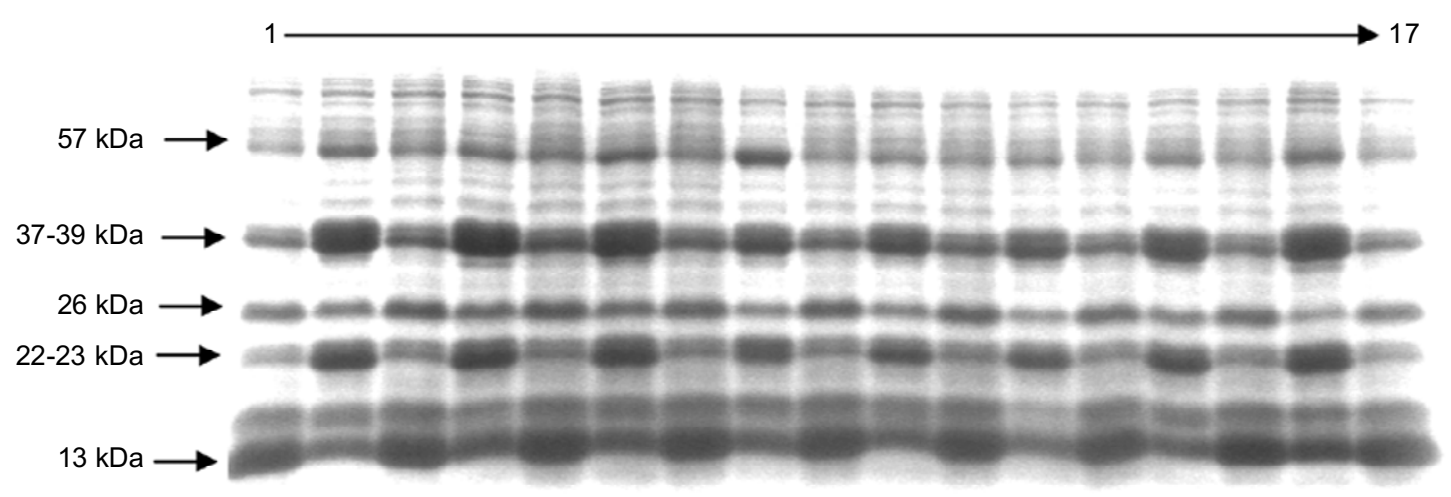

Fig. 7 SDS-PAGE analysis of W3660, eight varieties and corresponding $F_{1}$ seed. 1 to 17 are seeds of W3660, Xiangjing9707, Xiangjing9707/W3660, Xiangjing119, Xiangjing119/W3660, 9924, 9924/W3660, Zhendao88, Zhendao88/W3660, Wuyujing 3, Wuyujing 3/W3660, Zhendao99, Zhendao99/W3660, Wuyunjing 7, Wuyunjing 7/W3660, Jingrennuo, and W3660/Jingrennuo respectively.
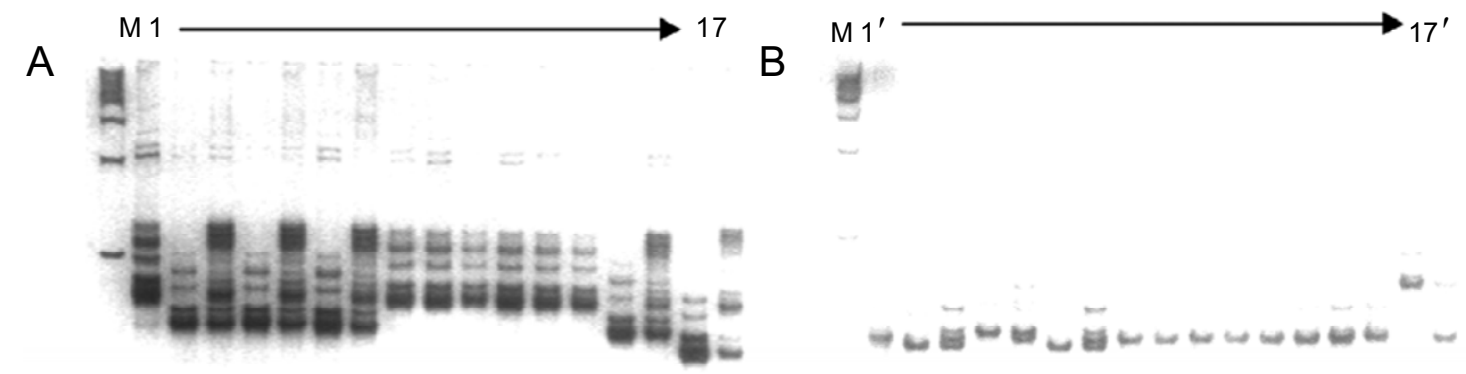

Fig. 8 Polymorphic analysis between W3660 and 8 varieties with RM1358 (A) and SSR2-004 (B). M represents DNA marker, 1 to 17 and 1 ' to 17' are W3660, Xiangjing9707, Xiangjing9707/W3660, 9924, 9924/W3660, Wuyunjing 7, Wuyunjing 7/W3660, Zhendao88, Zhendao88/W3660, Wuyujing 3, Wuyujing 3/W3660, Zhendao99, Zhendao99/W3660, Xiangjing119, Xiangjing119/W3660, Jingrennuo, and W3660/Jingrennuo, respectively.

\section{Marker-assisted selection}

SDS-PAGE analysis of the seed protein profiles of W3660 and seven Japonica varieties confirmed that low glutelin content is controlled by a dominant gene in all genetic backgrounds tested (Fig. 7). Of the six SSR markers (RM6639, RM5356, SSR2-001, SSR2-004, RM1358 and RM3501) linked to mutant gene, RM1358 was polymorphic between W3660 and Xiangjing 119, Xiangjing 9707, Wuyunjing 7 and 9924, as was SSR2-004 between W3660 and Xiangjing 9707, Wuyunjing 7 and 9924 (Fig. 8). The other four markers were monomorphic. These results indicated that the two markers flanking mutant gene are appropriate for marker-assisted selection of low glutelin content in the progeny of Japonica varieties. Further validation of RM1358 and SSR2-004 was carried out by genotyping of $188 \mathrm{~F}_{2}$ plants from the cross W3660 $\times$ Wuyunjing 7 (Tab. 3). This showed that both markers had high selection accuracy $(92.7 \%$ and $96.8 \%$, respectively). In a further validation experiment, analysis of $\mathrm{F}_{3}$ and $\mathrm{F}_{4}$ plants derived from the cross Wuyunjing $7 \times$ $\mathrm{W} 3660, \mathrm{~F}_{5}$ plants from Xiangjing $119 \times \mathrm{W} 3660, \mathrm{~F}_{4}$ plants from Xiangjing $9707 \times \mathrm{W} 3660$, and $\mathrm{F}_{3}$ plants from $9924 \times$ W3660, revealed that the protein phenotype of only one individual was inconsistent with genotype based on RM1358 and SSR2-004 scoring. We conclude that the use of RM1358 and SSR2-004 is appropriate for marker-assisted selection of low glutelin content in a Japonica background.

\section{DISCUSSION}

The demand for low-protein rice is expected to increase markedly as the number of at risk patients is increasing annually. Obtaining low-protein cultivars has become a significant new breeding goal to meet the needs of patients on a restricted protein diet. The low-glutelin content line W3660 has good agronomic traits compared with the Japa- 
Fine mapping and MAS of a low glutelin content gene in rice

Tab. 3 Efficiency of RM1358 and SSR2-004 for MAS for low glutelin content trait

\begin{tabular}{|c|c|c|c|c|c|c|c|c|c|c|c|}
\hline Combination & Generation & Total & Marker & AABB & $\mathrm{AaBb}$ & aabb & A_bb & aa $B_{-}$ & $\mathrm{AABb}$ & $\mathrm{AaBB}$ & Recombination rate \\
\hline \multirow{6}{*}{$\begin{array}{l}\text { Wuyunjing } \\
\text { 7/W3660 }\end{array}$} & $\mathrm{F}_{2}$ & 188 & RM1358 & 55 & 92 & 34 & 1 & 2 & 3 & 1 & $3.72 \%$ \\
\hline & \multirow{3}{*}{$\mathrm{F}_{3}$} & \multirow{3}{*}{24} & SSR2-004 & 57 & 93 & 35 & 0 & 1 & 1 & 1 & $1.60 \%$ \\
\hline & & & RM1358 & 18 & 1 & 5 & 0 & 0 & 0 & 0 & 0 \\
\hline & & & SSR2-004 & 18 & 1 & 5 & 0 & 0 & 0 & 0 & 0 \\
\hline & \multirow[t]{2}{*}{$\mathrm{F}_{4}$} & \multirow[t]{2}{*}{24} & RM1358 & 9 & 13 & 1 & 0 & 0 & 1 & 0 & $4.17 \%$ \\
\hline & & & SSR2-004 & 10 & 13 & 1 & 0 & 0 & 0 & 0 & 0 \\
\hline \multirow{2}{*}{$\begin{array}{l}\text { Xiangjing9707/ } \\
\text { W3660 }\end{array}$} & \multirow[t]{2}{*}{$\mathrm{F}_{4}$} & \multirow[t]{2}{*}{24} & RM1358 & 8 & 10 & 6 & 0 & 0 & 0 & 0 & 0 \\
\hline & & & SSR2-004 & 8 & 10 & 6 & 0 & 0 & 0 & 0 & 0 \\
\hline \multirow[t]{2}{*}{ 9924/W3660 } & \multirow[t]{2}{*}{$\mathrm{F}_{3}$} & \multirow[t]{2}{*}{24} & RM1358 & 16 & 8 & 0 & 0 & 0 & 0 & 0 & 0 \\
\hline & & & SSR2-004 & 16 & 6 & 0 & 0 & 0 & 0 & 0 & 0 \\
\hline $\begin{array}{l}\text { Xiangjing } \\
119 / \text { W3660 }\end{array}$ & $\mathrm{F}_{5}$ & 36 & RM1358 & 9 & 23 & 3 & 0 & 0 & 1 & 0 & $2.78 \%$ \\
\hline
\end{tabular}

A(a), phenotype of plants; A_, low glutelin content; aa, normal glutelin content; B(b), genotype at SSR marker loci; BB, homozygous for W3660 alleles; $\mathrm{Bb}$, heterozygous; bb, homozygous normal.

nese mutant LGC-1 when cultivated in Jiangsu Province, and is therefore of particular interest as a donor to develop new low glutelin varieties. The fine mapping of the low glutelin content gene in W3660 and the identification of tightly linked SSR markers will enable the use of markerassisted selection for this trait, and thus will facilitate the breeding of commercial cultivars with low glutelin content. In addition, the mapping of mutant gene provides the basis for its cloning and characterization, as well as the understanding of the biosynthesis of glutelin and the mechanism underlying the reduction of glutelin in W3660.

\section{Analysis of mapping results in W3660}

Mutant gene in W3660 was initially mapped to a region between 43.4 and $48.1 \mathrm{cM}$ on chromosome 2 . Novel markers derived from the whole genome sequence allowed the further definition of the genetic window to between SSR2001/SSR2-004 and RM1358, with distances of these markers to mutant gene of $1.1 \mathrm{cM}$ and $3.8 \mathrm{cM}$, respectively (Fig. 9A). It is known that LGC-1 mutant derived from chemical mutagenesis [2] has a phenotype similar to that of W3660. Miyahara K. et al [4] used an $\mathrm{F}_{2}$ population to map Lgc- 1 on rice chromosome 2 between RFLP markers XNpb 243 and G365, with gene-marker distances of $8.5 \mathrm{cM}$ and $39.1 \mathrm{cM}$, respectively (Fig. 9B). Kusaba et al [15] have recently described the cloning and functional analysis of $L g c-1$, and have proposed that the gene harbours a tail-to-tail inverted repeat consisting of a functional GluB4 gene and a truncated GluB5 gene (AB093593). This structure is thought to produce a GluB hairpin RNA with a dsRNA region. The latter have been implicated as potent inducers of RNA silencing, suggesting that RNA silencing is the

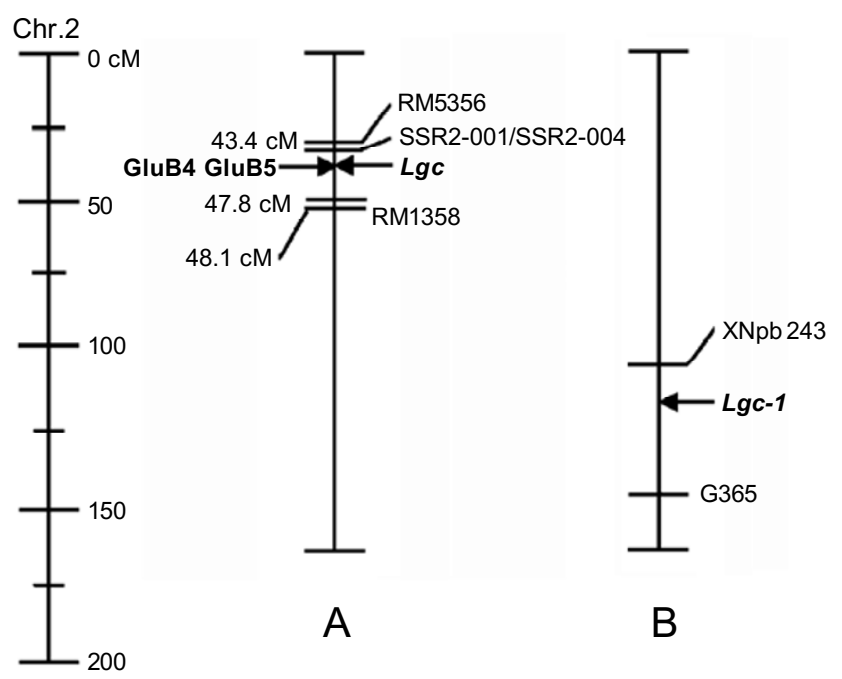

Fig. 9 Linkage map of the mutant gene in W3660 (A) and $L g c-1$ (B).

mechanism responsible for the low protein phenotype of LGC-1 [15]. The GluB4 and GluB5 sequences were used to assign $L g c-1$ to the assembled genomic sequence and to determine its position on the genetic map. RiceBLAST (http://riceblast.dna.affrc.go.jp/cgi-bin/robo-blast/blast2. cgi?dbname=Japonica) analysis indicated that GluB4 and GluB5 genes located in a region between $43.4 \mathrm{cM}$ and $47.8 \mathrm{cM}$ on chromosome 2 . Thus, the mutant gene in W3660 and $L g c-1$ are in the same region.

\section{W3660 and LGC-1 are two different mutants}

Although the mutant genes in W3660 and $L g c-1$ were 
located within the same region, W3660 and LGC-1 were obtained differently and may not necessarily represent same mutation. In $L g c-1$ mutant, most of the glutelin genes including members of GluB and GluA subfamilies are downregulated via RNA silencing mechanism mediated by dsRNA formed between GluB4 and GluB5 [15]. In W3660 mutant, we only observed decreased transcription of GluB5 gene, but not other members of Glutelin gene families including GluB4/GluB5 (Fig. 5 and unpublished data), suggesting that W3660 and LGC-1 are two different mutants. Since GluB5 coding sequence is located on Chromosome 2 between 37.0 to $37.4 \mathrm{cM}$, which is outside of our mapped mutation in W3660 on Chromosome 2 between 43.4 to $47.8 \mathrm{cM}$, then GluB5 transcription in W3660 probably has defect in transcriptional regulation other than mutations in GluB5 coding sequence through unknown mechanisms. Except for GluB4/GluB5, there are 150 genes found within the genomic region between SSR2004 and RM1358. However the biological functions of most of these genes are not known. It is thus unclear how the mutations occurring in W3660 were involved in glutelin synthesis. Mechanism of regulating GluB5 gene expression is probably involved. Although we cannot detect changes in GluB4/GluB5 gene transcription, the possibility of post-transcriptional regulation and translational regulation on GluB4/GluB5 cannot be excluded. Nevertheless, GluB5 gene is specifically reduced in W3660 mutant and is functionally correlated to the low glutelin content phenotype in W3660.

\section{SSR marker-assisted selection}

Marker-assisted selection has become routine for rice in recent years. Its successful use relies on the availability of high throughput markers tightly linked to the trait under selection. In this study, we have identified a number of SSR markers tightly linked to mutant gene in W3660. However, among these only the two loci RM1358 and SSR2-004 were polymorphic between the donor line W3660 and a number of tested Japonica varieties. In general there is a positive relationship between the number of repeats in a microsatellite sequence and the level of polymorphism at the locus. Both of the polymorphic loci were relatively large (the standard allele of RM1358 consists of $24 \mathrm{AG}$ repeats, while SSR2-004 carries 16 CTT repeats), and this may explain why only these loci were informative. We observed single crossing-over events between mutant gene and RM1358 or SSR2-004 in derived $\mathrm{F}_{3}$ population, respectively, only 16 or 5 progenies. Thus the selection accuracy of both markers was very high, irrespective of genetic background. Although selection based on a single marker is sufficient for breeding purposes, the simultaneous use of both markers should deliver a selection ac- curacy of $99.8 \%$. In the present study, no double crossing-over events were observed in 442 plants from the derived $\mathrm{F}_{3}$ progeny of $\mathrm{W} 3660 \times$ Jingrennuo, and 188 plants from the $\mathrm{F}_{2}$ progeny of Wuyunjing $7 \times \mathrm{W} 3660$. In conclusion we suggest that genotyping with RM1358 and SSR2004 will facilitate the breeding of low glutelin content rice varieties from Japonica $\times$ Japonica crosses, while RM1358, SSR2-001, SSR2-004 and RM5356 are suitable for selection in progeny of Indica $\times$ Japonica crosses. This provides a standard starting point for the breeding of low glutelin content rice varieties in China.

\section{ACKNOWLEDGEMENTS}

This research is supported by the grants from Hi-Tech Research and Development Program of China ("863" Program, No. 2003AA222131; 2003AA207020), the National Natural Science Foundation of China (No.30170570), Special Program for gene-transferring (No.JY03-B-07, JY03-A-07-02). The authors thank www.smartenglish.co.uk for linguistic correction of the manuscript.

Received, May 22, 2005

Revised, July 29, 2005

Accepted, Aug 16, 2005

\section{REFERENCES}

1 Mann C. Reseeding the green revolution. Science 1997; 277: 1038-43.

2 Iida S, Amano E, Nishio T. A rice (Oryza sativa L.) mutant having a low content of glutelin and a high content of prolamin. Theor Appl Genet 1993; 87:374-8.

3 Mochizuki T, Hara S. Usefulness of the low protein rice on the diet therapy in patients with chronic renal failure. Nippon Jinzo Gakkai Shi 2000; 42:24-9.

4 Miyahara K. Analysis of LGC-1, low glutelin mutant of rice. Gamma Field Symposia 1999; 38:43-52.

5 Jiang SM, Zhu SS, Liu SJ, et al. Screening and Genetic analysis of rice glutelin mutant. Yi Chuan Xue Bao 2003; 30:641-5.

6 Cagampang GB, Cruz LJ, Espiritu SG, Santiago RG, Juliano BO. Studies on the extraction and composition of rice proteins. Cereal Chem 1966; 43:145-55.

7 Iida S, Kusaba M, Nishio T. Mutants lacking glutelin subunits in rice: mapping and combination of mutated glutelin genes. Theor Appl Genet 1997; 94:177-83.

8 Laemmli UK. Cleavage of structural proteins during the assembly of the head of bacteriophage T4. Nature 1970; 227:680-5.

9 Dellapporta SL, Hicks JB. A new plant DNA minipreparation: Version II. Plant Mol Biol Rep 1983; 1:19-21.

10 Temnykh S, Park WD, Ayres N, et al. Mapping and genome organization of microsatellite sequences in rice (Oryza sativa L.). Theor Appl Genet 2000; 100:697-712.

11 McCouch SR., Teytelman L, Xu Y, et al. Development and mapping of 2240 new SSR markers for rice (Oryza sativa L.). DNA Res 2002; 9:199-207.

12 Chen X. Temnykh S, Xu Y, Cho YG, McCouch SR. Development of a microsatellite framework map providing genome-wide 
coverage in rice (Oryza sativa L.). Theor Appl Genet 1997; 95: 553-67.

13 Sanguinetti CJ, Dias NE, Simpson AJG. Rapid silver staining and recovery of PCR products separated on polyacrylamide gels. Biotechniques 1994; 17:915-9.

14 Lander ES, Green P, Abrahamson J, et al. MAPMAKER: an interactive computer for constructing primary genetics linkage maps of experimental and natural population. Genomics 1987; 1:174-81.

15 Kusaba M, Miyahara K, Iida S, et al. Low glutelin content1: a dominant mutant that suppress the glutelin multigene family via RNA silencing in rice. Plant Cell 2003; 15:1455-67. 